\title{
Mechanical Properties of Specimens 3D Printed with Virgin and Recycled Polylactic Acid
}

\author{
Isabelle Anderson
}

\begin{abstract}
With the $26 \%$ annual growth rate of additive manufacturing, especially in the area of 3D polymer printing, the amount of waste is increasing at a rapid rate. Limited research in the area of recycling has been produced, yet there are several recycling machines being developed for home use. Despite this work there is no published mechanical data on components produced with filament recycled from 3D printed parts. There is very limited data on mechanical properties of any 3D printed materials. This article compares the properties of parts 3D printed with virgin polylactic acid (PLA) to those printed with recycled PLA. Using commercially available PLA and an entry level 3D printer, tensile and shear specimens were produced and then tested for tensile yield strength, modulus of elasticity, shear yield strength, and hardness. The specimens were then ground up and reextruded into filament, and a second set of specimens were produced and tested using this recycled PLA filament. Mechanical testing showed that 3D printing with recycled PLA is a viable option. With the recycled filament, tensile strength decreased $10.9 \%$, shear strength increased $6.8 \%$, and hardness decreased $2.4 \%$. The tensile modulus of elasticity was statistically unchanged. Although the average mechanical properties before and after recycling were similar, there was more variability in the results of the recycled filament. Additionally, when printing with the recycled filament there was some nozzle clogging, while none occurred with the virgin filament. Overall, the mechanical properties of specimens 3D printed from recycled PLA filament were similar to virgin properties, encouraging further development in the area of recycling 3D printed filament.
\end{abstract}

Keywords: PLA, recycling, mechanical properties, 3D printing, additive manufacturing

\section{Introduction}

THE FIELD OF 3D PRINTING, also called additive manufacturing, has been growing at an exponential rate in the last few years. These terms refer to a range of processes that utilize various materials from thermoplastic filaments to powdered metals. ${ }^{1}$ The interest in these processes stems from their ability to produce components directly from a computer aided design model by digitally adding layer upon layer of material. ${ }^{2}$ This technology allows designers to quickly and inexpensively produce prototypes without tooling or machining. Some economists have considered this a third industrial revolution following mechanization and assembly line production. ${ }^{3,4}$ This industry has grown quickly in recent years to an annual value of over $\$ 5$ billion. Sales of 3D desktop printers were 160,000 in
2014 and grew to nearly 300,000 in $2015 .^{5}$ Some predictions have the 3D printing total market revenue at between $\$ 7$ and $\$ 23$ billion per year by 2020 . This increase is impressive, yet it is still a small fraction of the injection molded plastic market: currently valued at over $\$ 200$ billion. $^{6}$ The amount of 3D printed plastic compared to injection molded plastic will continue to increase as additive technologies and production speeds improve. The volume of 3D printing will never approach the volume of injection molding due to its mass production abilities. Although $3 \mathrm{D}$ printing is mostly used for prototypes and small production runs, there are some facilities that have the ability to produce runs of up to 5000 parts of certain shapes at competitive costs utilizing 3D printing.

Despite all of its benefits, 3D printing still creates a significant amount of waste. Some of the waste is due to failed prints

Longmeadow High School, Longmeadow, Massachusetts.

(C) Isabelle Anderson 2017; Published by Mary Ann Liebert, Inc. This is an Open Access article distributed under the terms of the Creative Commons Attribution License, which permits unrestricted use, distribution, and reproduction in any medium, provided the original work is properly cited. 


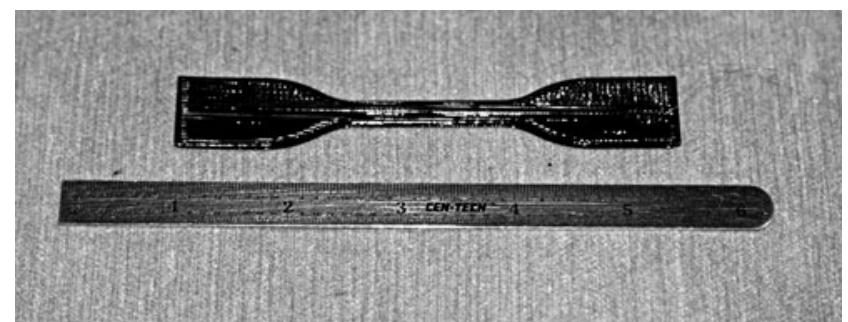

FIG. 1. ASTM D638-14 type IV tensile test specimen. ASTM, American Society of Testing Materials.

and discarded support structures. Additionally, many parts are created as disposable prototypes and since $3 \mathrm{D}$ printing is quick and inexpensive to produce, many iterations are often produced and then scrapped. In respect to thermoplastic 3D printed components, some materials such as acrylonitrile butadiene styrene (ABS) are produced using petroleum, whereas others, including polylactic acid (PLA), are based on plant materials.

Since PLA comes from plant materials such as corn starch and sugar cane, it is biodegradable. This allows several methods of managing scrap PLA including composting, combustion, recycling, and dumping in landfills. Of these methods recycling is by far the best in respect to environmental impact. Composting is not realistic due to the extreme conditions and time required to achieve full degradation. The environmental efficiency of combustion is limited by carbon dioxide production. Some preliminary work indicates that the environmental impact of recycling PLA is 50 times better than composting, and 16 times better than combustion. ${ }^{7,8}$ Recycled PLA has even less environmental impact than petroleum-based plastics: due to corn being a locally produced nonpetroleum substrate. PLA's carbon footprint is 3000 times less than some petroleum-based plastics. ${ }^{9}$

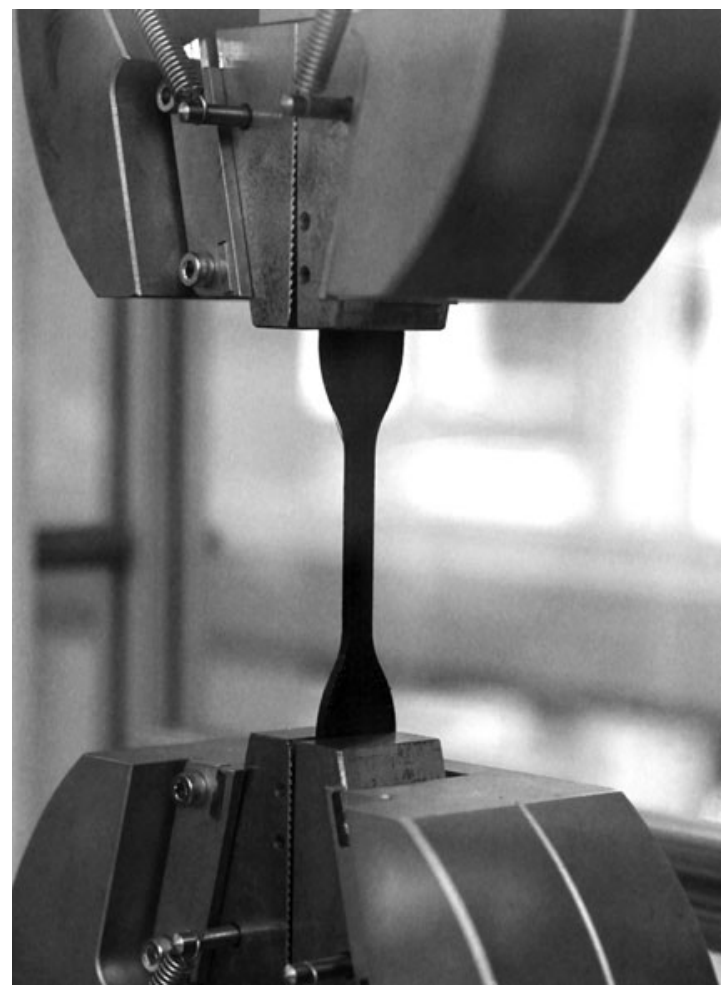

FIG. 2. Testing tensile specimens on the Instron 3369.

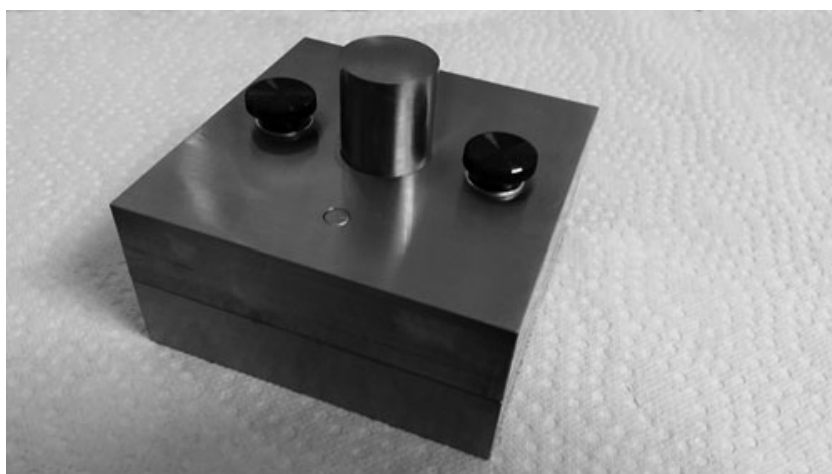

FIG. 3. ASTM shear testing fixture D732-10.

To address this waste in thermoplastic 3D printing, several corporations now offer recycled filament, produced from recycled consumer waste. Several companies even have home filament extruders that allow individuals to recycle materials using a benchtop system. When compared to centralized recycling, the concept of distributive recycling, where it is done at homes or businesses, has been found to potentially save over 100 million MJ of energy per year while reducing greenhouse gases. ${ }^{10}$

Although these advances are promising, there is currently very little data on the mechanical properties of virgin $3 \mathrm{D}$ printed plastics and almost no data available on recycled 3D printed plastics. ${ }^{11,12}$ Extruded PLA recycled 20 times in one study had minimal degradation in tensile strength or modulus. ${ }^{13}$ Different ratios of virgin to reground injection molded Polybutylene terephthalate and Polypropylene showed minimal decreases in their mechanical properties. ${ }^{14,15}$ A study where 3D printing PLA filament was recycled five times before component fabrication, found no decrease in mechanical properties other than a $10 \%$ reduction in elongation at failure. ${ }^{16}$

This study sets out to evaluate tensile, shear, and hardness properties of test specimens made with virgin PLA filament, and compare those results to specimens made from PLA filament produced from recycling the original 3D printed test specimens. PLA was chosen to be evaluated in this study based on its relative ease of recycling into filament compared to other plastics used for 3D printing.

\section{Materials and Methods}

Initial test specimens were produced using virgin PLA filament with a nominal diameter of $1.75 \mathrm{~mm}$. Tensile specimens were fabricated according to American Society of Testing Materials (ASTM) standard D638-14 Type IV

Table 1. Tensile Properties of Virgin Versus Recycled Polylactic Acid 3D Printed Specimens

\begin{tabular}{|c|c|c|c|}
\hline & Virgin & Recycled & T Test \\
\hline Number of specimens $(n)$ & 25 & 25 & \\
\hline $\begin{array}{l}\text { Average tensile yield } \\
\text { strength (Mpa) }\end{array}$ & 40.43 & 35.85 & $p=0.000003$ \\
\hline Standard deviation & 1.849 & 3.348 & \\
\hline $\begin{array}{l}\text { Average tensile modulus } \\
\text { of elasticity }(\mathrm{Mpa})\end{array}$ & 4258 & 4032 & $p=0.053546$ \\
\hline Standard deviation & 260 & 498 & \\
\hline
\end{tabular}



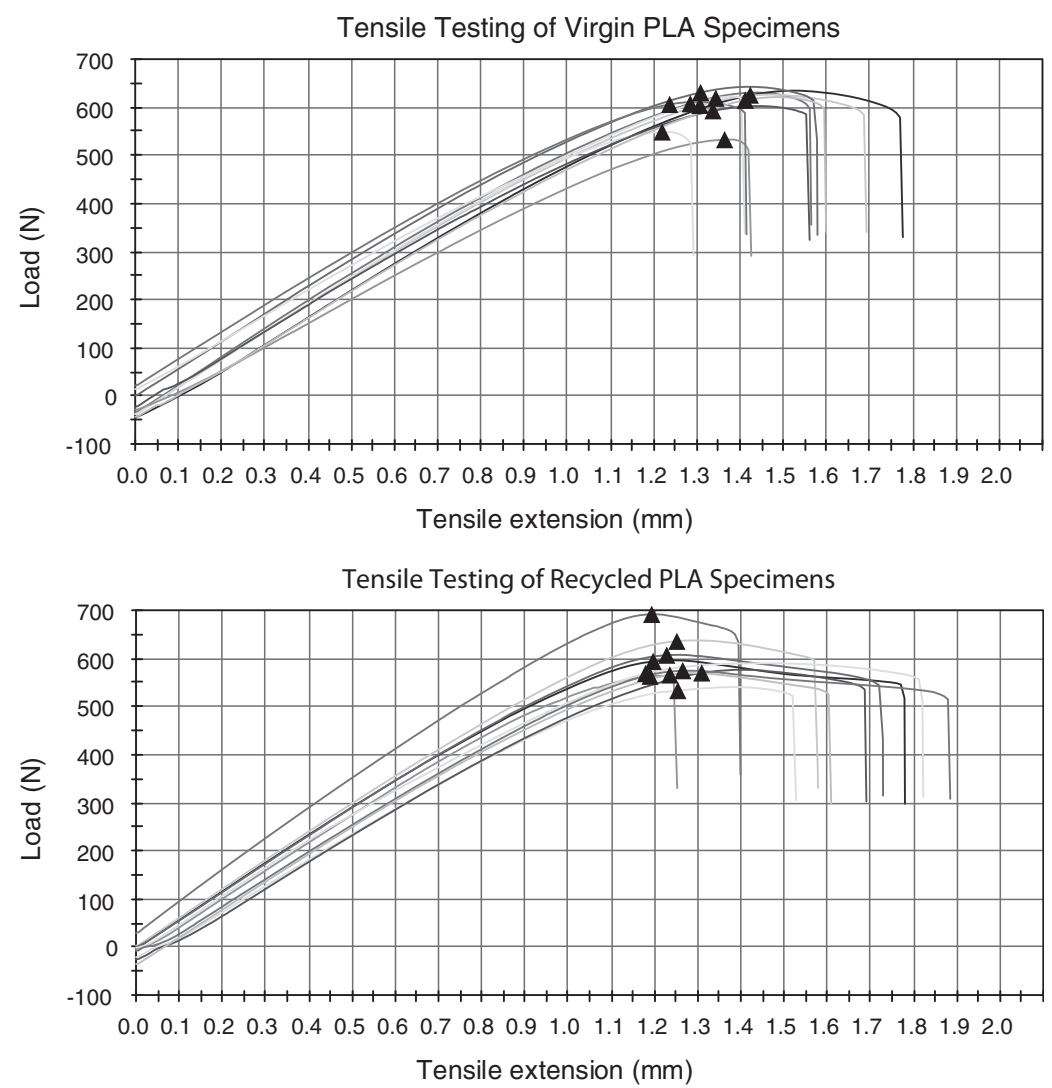

FIG. 4. Tensile load versus extension of virgin and recycled 3D printed PLA specimens. PLA, polylactic acid.

(Fig. 1). ${ }^{17}$ The shear specimens were fabricated as square plates with dimensions of $51.2 \times 51.2 \times 3.9 \mathrm{~mm}$. All specimens were produced on a Flashforge Creator driven by ReplicatorG version 0040 with Replicator 2 slicing defaults and rafting. The specimens were produced at $210^{\circ} \mathrm{C}$ with a $0.4 \mathrm{~mm}$ nozzle and an unheated build plate. Width and thickness of the tensile specimens and thickness of the shear specimens were measured using a digital micrometer with an accuracy of $0.01 \mathrm{~mm}$ at multiple points. The second set of specimens was produced with the same equipment, software, and settings.

Tensile testing was performed on a Instron 3369 Testing Machine with a head travel speed of $5 \mathrm{~mm} / \mathrm{min}$ (Fig. 2). Load and elongation were recorded to failure; separate extensometers were not utilized.

Shear testing was performed on the same Instron 3369 testing machine using an ASTM D732-10 shear punch tool (Fig. 3). ${ }^{18}$ Shear specimens were bolted into the punch tool jig and the Instron machine was used to compress the $25.4 \mathrm{~mm}$ rod through the center of the specimen with a head speed of $5 \mathrm{~mm} / \mathrm{min}$. Load and compressive extension were recorded until specimen failure.

Hardness was measured from the middle of the shear specimens, using a handheld Shore D digital durometer. Hardness was tested four times, recording the highest value to account for the possibility of the needle falling into small surface depressions.

After the initial set of specimens produced with virgin PLA filament were tested and photographed, they, along with extra specimens built at the same time with the virgin filament, were sent to the Filabot Company, a filament extruder, where they were ground and re-extruded into $1.75 \mathrm{~mm} 3 \mathrm{D}$ printing filament. The extrusion was done on a Filabot EX2, a bench top machine that can be used in homes. When the re-extruded filament was received the second set of tensile and shear specimens were produced using the same equipment, software, and method as used on the first set. These specimens were then tested with the same equipment and methods described above.

\section{Results}

Test results were produced with both virgin and recycled test specimens evaluating tensile, shear, and hardness properties. Tensile specimens, 25 of both virgin and recycled, were tested for tensile yield strength and tensile modulus of elasticity. The summary of these results are listed in Table 1 . The yield point was determined by using an offset of $0.11 \mathrm{~mm}$. The tensile modulus was estimated using a predetermined relationship between crosshead extension and strain using the tensile specimens. Based on Luke Perkins et al., at Cornell, this extension/strain ratio can be utilized to estimate strain without extensometers for similar materials. ${ }^{19}$ Plotting strain from extensometers versus cross head extension provided a

Table 2. Shear Strength of Virgin Versus Recycled Polylactic Acid 3D Printed Specimens

\begin{tabular}{|c|c|c|c|}
\hline & Virgin & Recycled & T Test \\
\hline Number of specimens $(n)$ & 31 & 31 & \\
\hline $\begin{array}{l}\text { Average shear yield } \\
\text { strength }(\mathrm{Mpa})\end{array}$ & 33.00 & 35.25 & $p=0.000024$ \\
\hline Standard deviation & 0.80 & 2.40 & \\
\hline
\end{tabular}



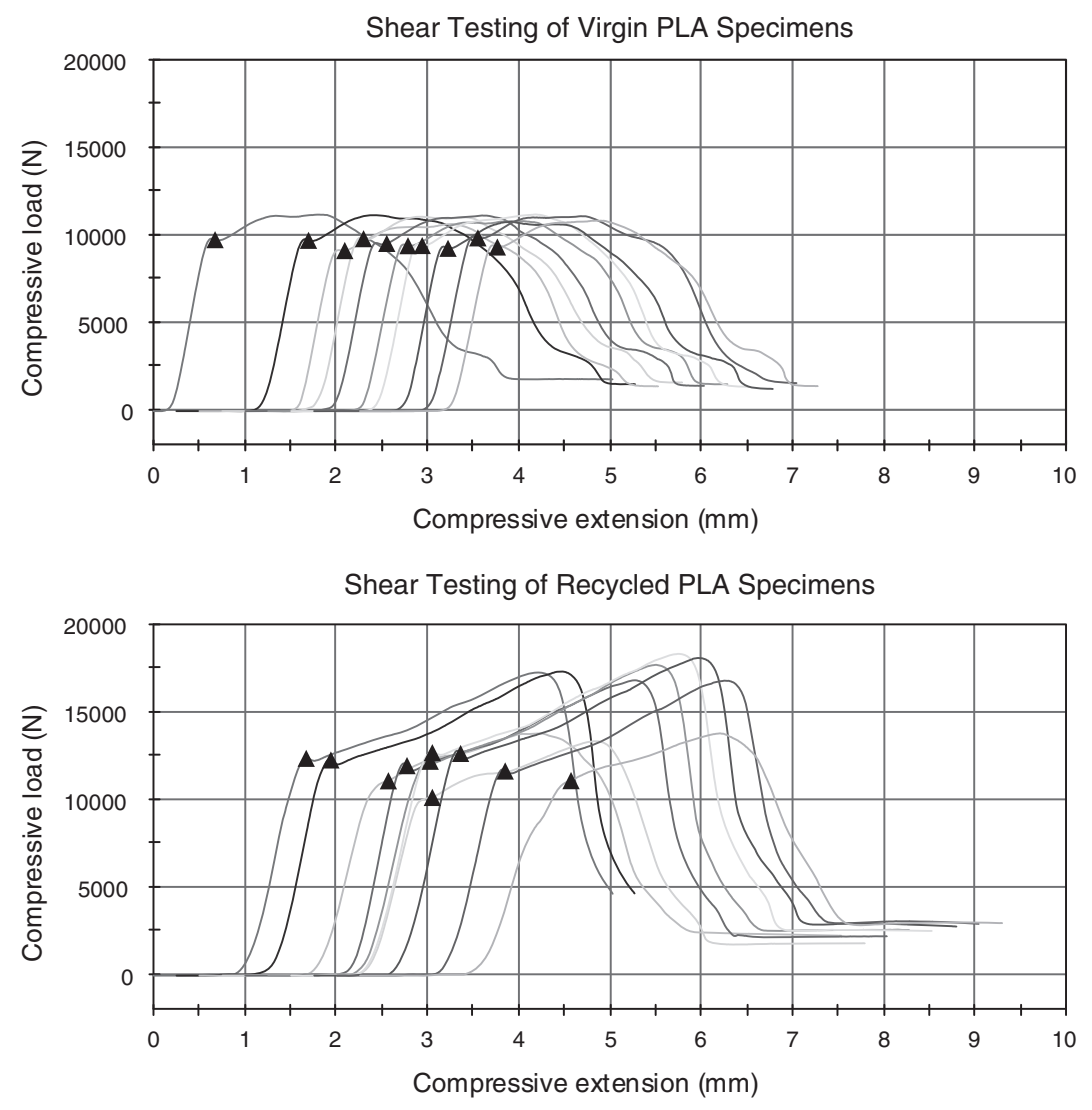

FIG. 5. Shear load versus extension of virgin and recycled 3D printed PLA specimens.

ratio of 0.243 strain/extension for the PLA tensile specimens. This method was used to estimate the strain from the crosshead extension for the modulus calculations. The tensile load versus extension graphs for 10 of the 25 virgin and recycled specimens, demonstrating consistent results, are shown in Figure 4.

Average shear strength values and statistical analysis are presented in Table 2. The shear load versus elongation curves for 10 of the 32 tests of both virgin and recycled specimens are displayed in Figure 5. Hardness data and statistical analysis are shown in Table 3.

\section{Discussion}

This project showing mechanical properties of specimens 3D printed with recycled filament that are similar to those of the virgin material is very encouraging for the advancement of recycling technology in the area of 3D printing. Mechanical properties of virgin material obtained

TABle 3. HaRdness of Virgin Versus Recycled Polylactic AcID 3D PRINTEd SPECIMENS

\begin{tabular}{lccc}
\hline & Virgin & Recycled & T Test \\
\hline $\begin{array}{l}\text { Number of specimens }(n) \\
\text { Average hardness }\end{array}$ & 32 & 32 & \\
$\quad$ (Shore D) & 84.8 & 82.8 & $p=0.000067$ \\
Standard deviation & 0.841 & 2.400 & \\
\hline
\end{tabular}

were in the same range of other published data for PLA and $3 \mathrm{D}$ printed PLA. ${ }^{20-22}$ Although there were some minor difficulties working with the recycled filament, it produced specimens with very usable properties. These data are some of the first with large sample sizes, of 25-32, showing tensile, shear, and hardness values for 3D printed PLA, in both a virgin and a recycled format. This verifies that, using an entry level 3D printer, components can be produced with filament recycled from previously 3D printed parts with consistent mechanical properties that are only slightly less than the original parts.

Although these recycled results are encouraging, there were several differences found when compared to the virgin material. The average mechanical properties of recycled specimens were generally lower than those of the virgin specimens, by $2-11 \%$. More notable was the increased variability in the results of the recycled material, as demonstrated by the increased standard deviations.

The decrease in properties such as tensile strength and hardness could be due to several factors. There could be a degradation in the properties of the recycled filament itself, or these results could come from problems in the $3 \mathrm{D}$ print such as in extrusion interruptions or limited interlayer adhesion. Since filament properties were not measured in this study, it is impossible to determine the individual contribution of these different factors. With the recycled filament there were some issues with nozzles clogging and subsequent printing issues, and this may have lead to some defects in the specimens. A possible problem with the filament re-extrusion is that a filter 
was not used and thus there could be some microscopic impurities that entered into the filament.

The recycled filament appeared identical to the virgin with consistent diameter and surface finish. Many sections of the recycled filament were checked for diameter when the nozzle clogs were occurring and they were all within the standard tolerances for $1.75 \mathrm{~mm}$ diameter filament.

The fact that the recycled average shear strength was $6.8 \%$ higher than the virgin was a surprising result that is not completely understood at this time. The specimens appeared to expand differently and one theory is that the material may have a different Poisson's ratio and, as the specimen was being compressed, it expanded against the sides of the shear jig. There could also be some microscopic changes in the interlocking of the extruded recycled PLA as it was laid down.

One other potential drawback of working with recycled filament is the possible increase in ultrafine particle emissions. When 3D printing thermoplastics at high temperatures both gases and particles are emitted. Specifically with ABS there have been emissions of carbon monoxide, hydrogen cyanide, and volatile organics. ${ }^{23}$ Ultrafine particle emission was found to be higher with ABS than PLA filament but both pose health risks. There have been some reports of higher particle emissions with recycled filaments possibly due to contaminates. This potential higher risk should be safeguarded against while further investigation is performed. To maintain a safe environment for working with 3D printing it is important to have proper ventilation. Enclosed desktop 3D printers with HEPA filters that are now on the market could also be considered for acquisition of future $3 \mathrm{D}$ printers to reduce these health risks. ${ }^{24}$

Overall, these results are very encouraging and support the development of recycling technology for 3D printing and the potential for home and small business recycling of 3D printed waste. The adoption of using recycled 3D printing filament has certain benefits but is not without risks. The benefits include lower $\mathrm{CO}_{2}$ production when creating recycled filament and a decrease of landfill usage. There is also the potential to reduce costs by recycling locally, where individuals, groups, or small businesses can procure recycling equipment in the range of $\$ 3000$. This investment could be recovered after production of roughly one hundred spools of filament. Despite the benefits there are possible risks of using recycled filament: nozzle clogs, mechanical property degradation, and increased particle release. Nozzle clogging can be reduced with further investigation on minimizing contamination, as well as research into utilizing larger nozzles and higher forming temperatures. Mechanical property degradation, as outlined in this article, is limited. Further work will need to be done to evaluate possible increased particle emissions but ventilation precaution measures should be taken. Additional studies evaluating the utility of recycled filament that is a blend of both virgin and recycled plastic in different portions may show better performance. In future work, more extensive use of extensometers may add to the data accuracy in the areas of elastic modulus. Testing of filament strands could show whether the decreased properties are due to filament strength or printability issues. ${ }^{25}$ These encouraging results on the performance of parts made with recycled PLA filament should be recreated with other plastics, such as ABS, to prove their viability and spread the benefits of filament recycling across the $3 \mathrm{D}$ printing industry.

\section{Conclusions}

In this research project PLA test specimens were made using a desktop 3D printer, tested for tensile, shear and hardness properties, then ground up and recycled into 3D printing filament. This recycled filament was used to 3D print identical specimens that again were tested and resulting values were compared to the original virgin specimen data. The recycled specimens demonstrated similar properties to the virgin, although slightly decreased in most areas with a moderate increase in property variation. Tensile yield strength decreased from 40.3 to $35.9 \mathrm{Mpa}$, tensile modulus decreased from 4258 to $4032 \mathrm{Mpa}$. Shear yield strength increased from 33.0 to $35.3 \mathrm{Mpa}$. Hardness changed from 84.8 to 82.8 on the Shore D scale. All differences between virgin and recycled were significant with $p$-values $<0.005$ except for tensile modulus. There were printing difficulties with the recycled filament, where it would clog the extrusion nozzle at times. Clogging may have been due to impurities, since filtering was not used in the reextrusion process. The increased variation seen in the recycled material properties could be due to variability in the recycled filament itself or the effect of printing difficulties on the final specimens. This project produces valuable baseline data on 3D printed PLA and validates the recycling process with similar data using recycled PLA. The data produced demonstrates that recycling $3 \mathrm{D}$ printed scrap materials into usable filament can yield parts with similar properties to parts produced with virgin filament. This creates the potential to save significant amounts of raw materials, cost, energy, and $\mathrm{CO}_{2}$ emissions in the production of 3D printed components.

\section{Acknowledgments}

Author wishes to thank Robert Anderson for assistance in the mechanical testing of the specimens, the Filabot Company for producing the recycled filament, and Kathleen Wells of Longmeadow High School for assistance with statistical analysis.

\section{Author Disclosure Statement}

No competing financial interests exist.

\section{References}

1. Kietzmann J, Pitt L, Berton P. Disruptions, decisions, and destinations: enter the age of 3D printing and additive manufacturing. Business Horizons 2015;58:209-215.

2. Gibson I, Rosen B, Stucker B. Additive manufacturing technologies: 3D printing, rapid prototyping, and direct digital manufacturing, 2nd Edition. Johnson Matthey Technology Review 2015;59:193-197.

3. Huang S, Liu P, Mokasdar A. Additive manufacturing and its societal impact: a literature review. Int J Adv Manuf Technol 2013;67:1191-1203.

4. A Third Industrial Revolution. The Economist April 21, 2012: The Economist. The Economist Newspaper. April 21, 2012.

5. Kira. Wohlers Report 2016 reveals $\$ 1$ billion growth in 3D printing industry. 3D Printing Technology. Wohlers Associates, Inc. 2016. www.3ders.org/articles/20160405-wohlersreport-2016-reveals-1-billion-growth-in-3d-printing-industry .html (Accessed May 22, 2017).

6. Columbus, Louis. 2015 Roundup Of 3D Printing Market Forecasts And Estimates Online Blog Posting. www.forbes 
.com/sites/louiscolumbus/2015/03/31/2015-roundup-of3d-printing-market-forecasts-and-estimates/\#482faf951 dc6 (Accessed December 19, 2016).

7. Slijkoord, Jan Willem. Is recycling PLA really better than composting?, Online News post. https://3dprintingindustry .com/news/is-recycling-pla-really-better-than-composting49679 (Accessed December 18, 2016).

8. Vink, Erwin TH, Rabago, Karl R, et al. Applications of life cycle assessment to NatureWorks polylactide (PLA) production. Polym Degrad Stab 2003;80:403-419.

9. Shen J. Comparative Life Cycle Assessment of Polylactic Acid (PLA) and Polyethylene Terephthalate (PET). Nature .berkeley.edu. Berkeley, Apr.-May 2011. Web. 18 Dec. 2016. https://nature.berkeley.edu/classes/es196/projects/2011final/ ShenJ_2011.pdf.

10. Kreiger M, Mulder M, Glover M, et al. Life cycle analysis of distributed recycling of post-consumer high density polyethylene for 3-D printing filament. J Clean Prod 2014;70:90-96.

11. Tymrak B, Kreiger M, Pearce J. Mechanical properties of components fabricated with open-source 3-D printers under realistic environmental conditions. Mater Design 2014;58: 242-246.

12. Kreiger M, Anzalone G, Mulder M, et al. Michigan Technological University. Distributed Recycling of PostConsumer Plastic Waste in Rural Areas. MRS Online Proceedings Library, 2013, 1492, mrsf12-1492-g04-06. http:// digitalcommons.mtu.edu/materials_fp/51 (Accessed October 30, 2016).

13. Peinado V, Castell P, García L, Fernández Á. Effect of extrusion on the mechanical and rheologicalproperties of a reinforced poly (Lactic Acid): reprocessing and recycling of biobased materials. Materials 2015;8:7106-7117.

14. Gu F, Hall P, Miles N, Ding Q, Wu T. Improvement of mechanical properties of recycled plastic blends via optimizing processing parameters using the Taguchi method and principal component analysis. Mater Design 2014;62:189-198.

15. Dulebová L, Greškovič F. Influence of regrind on properties of plastics processing by injection moulding. Mater Eng 2011;18:44-48.

16. Cruz F, Lanza S, Boudaoud H, Hoppe S, Camargo M. Polymer Recycling and Additive Manufacturing in an Open
Source Context: Optimization of Processes and Methods. Tech. Print.

17. ASTM D638-14 Standard Test Methods for Tensile Properties of Plastics. West Conshohocken, PA: ASTM International, 2010.

18. ASTM D732-10 Standard Test Method for Shear Strength by Punch Tool -Standard Test Methods for Tensile Properties of Plastics. West Conshohocken, PA: ASTM International, 2010.

19. Perkins L, Lobo H. Cornell University and Datapoint Labs. A Novel Technique to Measure Tensile Properties of Plastics at High Strain Rates. www.datapointlabs.com/testpaks/ antec2005.htm (Accessed October 30, 2016).

20. Lanzotti A, Grasso M, Staiano G, et al. The impact of process parameters on mechanical properties of parts fabricated in PLA with an open-source 3-D printer. Rapid Prototyping J 2015;21:604-617.

21. Fernandez-Vicente M, Calle W, Ferrandiz S, et al. Effect of infill parameters on tensile mechanical behavior in desktop 3D printing. 3D Printing and Additive Manufacturing. 3;3: 2016.

22. Botfeeder Canada. ABS vs PLA Comparison Table. www .botfeeder.ca/ABS-VS-PLA (Accessed October 30, 2016).

23. Rutkowski Joseph V, Barbara C. Levin. AcrylonitrileButadiene-Styrene Copolymers (ABS): pyrolysis and combustion products and their toxicity-a review of the literature. Fire Mater 1986;10:93-105.

24. Stephens B, Azimi P, Orch Z, Ramos T. Ultrafine particle emissions from desktop 3D printers. Atmos Environ 2013; 79:334-339.

25. Baechler C, Devuono M, Pearce J. Distributed recycling of waste polymer into RepRap Feedstock. Rapid Prototyping J 2013;19.2:118-125.

Address correspondence to: Isabelle Anderson

Suite 1

35 Bridge Street

Belchertown, MA 01007

E-mail: izzyander@yahoo.com 